\title{
OS PORQUÊS DA CRIANÇA NA PSICOLOGIA GENÉTICA DE PIAGET E NA PSICANÁLISE E A DIFICULDADE DE APRENDIZAGEM*
}

Cristia Rosineiri Gonçalves Lopes Correa

Cristia Rosineiri Gonçalves Lopes Correa Psicanalista, doutora em Educação pela Universidade Federal de Juiz de Fora (UFJF/ MG). Mestre em Filosofia e Ética da Saúde Mental pela University of Warwick (Inglaterra). Mestre em Educação pela UFJF. Membro da Associação Mundial de Psiquiatria e do Ato Freudiano Escola de Psicanálise de Juiz de Fora.
RESUMO: Aborda-se a dimensão do enigma na dificuldade de aprendizagem e, por conseguinte, a importância dos porquês intermináveis da criança em uma determinada fase. Para isso, trabalha com a interlocução entre o argumento de Piaget e a abordagem psicanalítica acerca dos referidos porquês infantis. Argumenta-se que embora a aprendizagem se sustente na suposição do saber do Outro, em muitos quadros, podemos verificar padecimentos nas aprendizagens devido à ausência da sustentação do enigma introduzido pelo saber inconsistente do Outro, cuja matriz são as investigações infantis com todos os seus porquês.

Palavras-chave: Porquês infantis, dificuldade de aprendizagem, Piaget, Freud, Lacan.

ABSTRACT: The whys of the children in Piaget's genetic psychology and psychoanalysis and learning difficulty. This article discusses the role played by the enigma in the learning difficulty and, consequently, the relevance of the child's interminable whys which take place at a specific stage. With this purpose, this article brings a conversation between Piaget's argument and the psychoanalytic approach about the referred child's whys. In this sense, this article argues that even though learning is sustained on the assumption of the Other's knowledge, in different contexts, we can verify learning failures due to the absence of sustainability of the enigma introduced by the Other's inconsistent knowledge, whose matrix are the child's investigations with all their whys.

Keywords: Child's whys, learning difficulty, Piaget, Freud, Lacan.

DOI - http://dx.doi.org/10.1590/S1516-14982015000200009

\footnotetext{
* O presente artigo é uma versão ampliada do trabalho com o mesmo nome apresentado pela autora no X Encontro de Pesquisa em Educação da Região Sudeste - Pós-Graduação em Educação na Região Sudeste em suas Múltiplas Dimensões (Anpedinha), na Universidade Federal do Rio de Janeiro, ocorrido no período de 10 a 13 de julho de 2011. Constitui-se também como uma parte da Dissertação de Mestrado em Educação defendida no mesmo ano. Agradeço especialmente à Ana Maria Moraes Fontes, pela orientação no Mestrado em Educação da UFJF, referido acima, e também aos sinais recebidos quando da apresentação no citado Congresso, os quais permitiram depurar essa escrita e muito contribuíram para a presente versão ampliada.
} 


\section{PIAGET E OS PORQUÊS DA CRIANÇA NO TEMA DO EGOCENTRISMO INFANTIL}

Piaget (1964), dentro da sua abordagem do estágio pré-operatório ou da inteligência intuitiva, que compreende a segunda parte da primeira infância, ou seja, de 2 a 7 anos, argumenta que o surgimento da linguagem modifica profundamente as condutas da criança no aspecto afetivo e no intelectual. Fala de três modificações gerais nessa conduta: socialização, pensamento e intuição. Pretendemos, aqui, para não ultrapassar o limite da análise pretendida, abordar apenas a modificação concernente ao pensamento.

No que toca ao pensamento, Piaget afirma que nesse período compreendido entre 2 e 7 anos, podemos encontrar o pensamento egocêntrico caracterizado pelo finalismo, animismo e antropomorfismo. Importante observar inicialmente que o que Piaget chama de "pensamento egocêntrico" na criança comporta como núcleo central a confusão do eu com o mundo exterior e, por conseguinte, a falta de cooperação.

No entanto, tal pensamento egocêntrico manifesta-se de duas maneiras: uma relacionada ao aspecto cognitivo e, outra, ao aspecto social, a despeito de o egocentrismo, em suas duas formas, constituir um único e mesmo fenômeno. Piaget indica que se trata na formulação de egocentrismo, em sua essência, de uma ausência de percepção por parte da criança quanto à existência dos outros ou de uma vontade diferente da dela.

Ademais, trata-se de uma ausência de percepção do que é certo ou errado, na própria medida em que o ponto de vista próprio é julgado como o único possível. O egocentrismo se constituiria a partir da centralização da criança em si mesma no sentido de uma ausência de relativização intelectual, tomando por única realidade aquela que surge à percepção própria, coordenando exclusivamente a própria perspectiva. “A criança pequena tem extrema dificuldade em se colocar no ponto de vista do outro, fato que a impede de estabelecer relações de reciprocidade" (LA TAILLE, 1992, p.15).

Dito isso, importa, assinalar que Piaget (1964) privilegia como uma verdadeira fonte do pensamento espontâneo da criança que ajuda a evidenciar a modalidade egocêntrica do pensamento dessa fase a análise das abundantes perguntas que a criança faz, "às vezes, quase ao mesmo tempo em que fala” (p.29), ou seja, os seus porquês intermináveis e incansáveis que Piaget qualifica como uma forma básica de pergunta que aparece desde os 3 anos e, muitas vezes antes, tende a se multiplicar até os 6 anos.

Para Piaget, enquanto no adulto o sentido geral do "porquê" pode comportar dois diferentes significados, a saber, a "finalidade": "por que você vai por este caminho?" (p.29) ou a "causa eficiente":"por que os corpos caem?" (idem, ibidem), na criança, o que ocorre é que esses famosos "porquês”, que muito frequentemente embaraçam tanto o adulto que se vê em dificuldade de respon- 
der, apresentam "um significado indiferenciado, meio caminho entre o fim e a causa, implicando, no entanto, um e outro ao mesmo tempo” (idem, ibidem).

\begin{abstract}
“'Por que é que está rolando?', pergunta, por exemplo, um menino de 6 anos à pessoa que toma conta dele. Refere-se a uma bola de gude que, em um terraço levemente inclinado, dirige-se à pessoa situada na parte mais baixa; como resposta dir-se-á: ‘Porque inclinado', o que é uma explicação puramente causal; mas a criança, não satisfeita, pergunta novamente: ‘Ela sabe que você está embaixo?’ Seguramente, não se deve tomar ao pé da letra esta reação: a criança não empresta à bola de gude uma consciência humana. Se bem que exista, como veremos, uma espécie de 'animismo' infantil, não se poderia interpretá-lo como um antropomorfismo tão grosseiro. Todavia, a explicação mecânica não satisfaz à criança, porque ela entende um movimento como necessariamente orientado para um fim e, em consequência, como intencional e dirigido. Portanto, é a causa e o fim do movimento da bola de gude que esta criança queria conhecer, e é por isto que este exemplo é tão representativo dos 'porquês' iniciais.” (PIAGET, 1964, p.29-30)
\end{abstract}

De acordo com Piaget, um dos motivos do caráter de obscuridade comportado por esses porquês infantis que introduzem tantos embaraços para o adulto responder à criança se devem ao fato de grande parte deles estar relacionada a fenômenos ou acontecimentos ocorridos ao acaso e que, por conseguinte, não comportam os porquês. Ademais, Piaget verifica que o embaraço e a dificuldade em responder a eles não tomam lugar em crianças da mesma idade daquela que está perguntando. Nessa direção, ressalta das respostas dadas que para essa fase "não há acaso na natureza, porque tudo é 'feito para' os homens e crianças, segundo um plano sábio e estabelecido, no qual o ser humano é o centro" (idem, ibidem).

“Assim, é que o mesmo menino de 6 anos, cuja reação ao movimento acabamos de descrever, espanta-se que haja em Genebra dois Salève, enquanto que não há dois Cervin em Zermatt: 'Por que existem dois Salève?' Outro dia pergunta: 'Por que o lago de Genebra não vai até Berna?’ Não sabendo como interpretar estas perguntas estranhas, resolvemos propô-las a outras crianças da mesma idade, perguntando-lhes o que teriam respondido a seu companheiro. A resposta para eles não apresentou nenhuma dificuldade: há um Grande Salève para os grandes passeios e adultos, e um Pequeno Salève para os pequenos passeios e para as crianças, e o lago de Genebra não chega até Berna porque cada cidade deve ter o seu lago.” (PIAGET, 1964, p.30)

A conclusão de Piaget sobre essas intermináveis perguntas "estranhas”, de caráter "obscuro", fonte de "embaraços" e "dificuldades”, por excelência, é 
que a criança, ao fazê-las, ao permanecer no exercício dessa série incansável de porquês, procura a "razão de ser" das coisas. "Razão de ser" das coisas que tem como premissa fundamental a existência de uma razão para tudo, se constituindo, portanto, em uma razão causal e finalística que exclui por completo a dimensão do acaso com os seus fenômenos e acontecimentos fortuitos. Assim, justamente por essa explicação pautada na dimensão da racionalidade, conclui que nessas abundantes perguntas infantis está em jogo um "fracasso" diante dos fenômenos fortuitos comportados pelo acaso.

Aqui, cabe fazer um pequeno assinalamento sobre essa dimensão do acaso percebida por Piaget, a partir do fato de que sua abordagem nos faz lembrar da Física de Aristóteles (s.d. [1999]), em que, esse filósofo, em sua teoria dos princípios, nos oferece a teoria das quatro causas: 1) a causa material; 2) a causa eficiente; 3) a causa formal; e 4) a causa final. Primeiramente, importa, para o que está sendo abordado aqui, aproveitar o momento para falar, mesmo que bem pouco, da "causa final" e da "causa eficiente", pelo fato de Piaget apontar que é delas que se trata na dimensão das perguntas feitas pelo adulto, no sentido de uma escolha exclusiva: um ou outro, mas não ambos(COPI, 1978), e que na dimensão dos incansáveis porquês infantis, trata-se justamente de uma impossibilidade da criança, nessa fase, de operar com esse “ou”exclusivo. E justamente por tal impossibilidade a criança, nessa fase, termina por operar com uma lógica própria: "um e outro, meio caminho". Isso, além do seu fracasso em manejar com a dimensão do acaso presente nos fenômenos ou acontecimentos fortuitos.

Interessante falar um pouco da causa final e da causa eficiente, porque no uso que Piaget faz desses termos, dentro do contexto abordado por ele, ainda que não faça referência à Física de Aristóteles, parece que está referenciado nesse trabalho. Pensamos não ser uma simples coincidência o fato de, articulada com essa indicação das causas final e eficiente, ele vá abordar a dimensão do encontro com o acaso, feito pela criança, nesse estágio, na sua análise das abundantes perguntas infantis. Argumentamos que tais elementos justificam nossa hipótese de que devemos buscar nessa referência aristotélica alguma coisa, ainda que mínima, que nos permita avançar um pouco mais nessa questão dos intermináveis porquês da criança.

Assim, sobre a causa final e a causa eficiente, podemos dizer, a princípio em relação à causa final que ela diz respeito à finalidade, de maneira geral, sendo aquilo pelo que o efeito é produzido. Constitui, portanto, o termo da ação no plano da execução e o princípio da ação no plano da intenção. A finalidade é simultaneamente o princípio e o termo da ação. A causa final é de natureza teleológica, ou seja, o que vem por fim determina o início do processo causal, conferindo uma inversão entre causa e efeito. A pergunta básica da causa final ao invés de ser "por que isto acontece?” é "para que isto acontece?". 
Sobre a causa eficiente, cabe dizer que ela é aquela que, por sua ação física, produz o efeito. Constitui o motivo da mudança ou transformação de um objeto. Em geral, a causa eficiente é chamada de causa stricto sensu. Nessa modalidade, as partes interagem entre si determinando causalmente o todo. Em uma escultura de mármore, o mármore é a sua causa material, o escultor e suas ferramentas são as suas causas eficientes primária e secundária, a maquete e sua forma serão a causa formal e a finalidade artística ou decorativa da escultura será a causa final.

Feita a consideração sobre a causa final e a causa eficiente, podemos passar à dimensão do acaso comportado pelos fenômenos ou acontecimentos fortuitos, também presentes na Física de Aristóteles. Sobre esse ponto, cabe dizer que, embora sejam quatro os gêneros da causa, na filosofia aristotélica é possível um agente causar acidentalmente uma transformação para a qual ele não era movido por causalidade. Quando isso ocorre, diz-se que o efeito ocorreu por acaso, e a causa é acidental, na própria medida em que os efeitos terão uma causa eficiente, mas não causará estes efeitos per se, mas por acidente.

Assim, no seu estudo sobre as causas que produziam os diferentes efeitos na realidade, Aristóteles apontou duas causas cuja eficiência escapa por falta de intencionalidade. Nessa dimensão da causa acidental, o autor vai dividi-la em dois tipos: tique e autômaton. Autômaton e tique foram traduzidas "impropriamente" (LACAN, 1964a/1988, p.54) por “acaso”e “fortuna”ou “sorte”, respectivamente. De acordo com Aristóteles, autômaton diferencia-se da tique por ser uma noção mais ampla, na própria medida em que tudo que se deve à "fortuna” ou à "sorte", deve-se também ao "acaso", mas nem tudo que se deve ao "acaso" se deve à "fortuna” ou à "sorte”. Ao ler essa abordagem aristotélica, podemos dizer que ambas as dimensões comportadas pela causa acidental concernem à dimensão do "acaso". Mas também podemos dizer que enquanto a noção de autômaton parece designar o "acaso"significante, a tique pode ser lida como o "acaso" do real: “o encontro faltoso, para além do jogo dos signos e de seu retorno" (LOPES \& VINHEIRO, 1999, p.79), a dimensão do que se repete como falta.

Importa muito, nesse ponto, a referência a Alberti (1996), que diz que em Aristóteles enquanto autômaton circunscreve a causa não deliberada, ou seja, espontânea, tiquê, apesar de implicar o acidente, traz em seu cerne certa dose de deliberação, certo grau de escolha.

\footnotetext{
"Por acaso há um encontro, mas esse encontro, essa chance, equaciona com ananké, a necessidade física cega, que não tem representação no mundo dos significantes. 'Sorte’ (tykhé) 'é plantar e dar'. 'Sorte é merecer e ter', já dizia Guimarães Rosa, pois nem sempre plantando dá, nem sempre quem merece tem. A maneira pela qual o sujeito sofre acidentalmente o trauma e seus efeitos implica, então, esta certa dose de deliberação." (ALBERTI, 1996, p.190)
} 
Lendo Piaget, encontramos uma abertura, portanto, de pensarmos que parece que a dimensão do acaso comportada pelos fenômenos e acontecimentos fortuitos, percebida nos incansáveis porquês da criança, está pautada na abordagem da causalidade feita por Aristóteles em sua Física. Dentro da nossa perspectiva, isso não é qualquer coisa, pois da abordagem feita por Lacan (1964a/1988), dos porquês da criança, podemos extrair uma referência à mesma Física aristotélica, ainda que nesse exato ponto da análise lacaniana dos porquês infantis não encontremos essa referência explícita — só poderemos encontrá-la como o resultado de um percurso pelo seminário Os quatro conceitos fundamentais da psicanálise.

Veremos o porquê daqui a pouco e na nossa discussão mais adiante.

Mas uma vez que existem em Aristóteles duas causas acidentais concernentes ao acaso, tique e autômaton, fazendo Aristóteles uma certa diferenciação entre elas no sentido de que o autômaton se refere ao acaso espontâneo e a tique comporta certa dose de deliberação que toca na questão de certa intencionalidade e responsabilidade em jogo, podemos de saída dizer que Piaget deixou implícito que o acaso que ele lê nos referidos porquês é o acaso espontâneo. Isso porque, em exemplos que dá dessas abundantes perguntas infantis nas quais ressalta a pergunta da criança pela dimensão da intencionalidade, Piaget fala de um "fracasso" diante da dimensão do acaso, deixando-nos pensar que o acaso considerado por ele não dá lugar para esse elemento da deliberação. É preciso dizer que Piaget, de modo perspicaz, percebe que não se trata de atribuir esse elemento à característica do “animismo”. Mas não percebe a importância de tomar sob consideração certa dose de deliberação comportada por uma dessas causas concernentes ao acaso.

Pensamos que ainda que as perguntas infantis dentro dessa matriz dos porquês intermináveis ocorram em relação a coisas que não comportem certa dose de deliberação, a tomada sob consideração disso introduz nova nuance, a saber, a nuance que diz do embaraço infantil com esse acaso que não abole suas relações com a causalidade.

Como veremos na próxima seção, é justamente esse embaraço que Lacan (1964a/1988) privilegiará em sua análise dos porquês infantis, na própria medida em que a pergunta pelo desejo do Outro que é o que ele diz estar em jogo nessas incansáveis perguntas infantis é introduzida justamente pelo encontro traumático do sujeito com a castração no Outro, ou seja, o encontro com o real. Pois, se nesse mesmo seminário, Lacan precisa que esse encontro com o real trata da incidência da tiquê, na própria medida em que nesse encontro faltoso o que está em jogo é o acaso com certa dose de deliberação, então a pergunta pelo desejo do Outro introduzida pelo encontro tíquico (tiquê), presente nos porquês infantis, refere-se a uma pergunta pelo acaso que não abole as suas relações com a causalidade, a saber, a causa do desejo do Outro. Com Lacan, podemos dizer que é isso que podemos ler nas incansáveis perguntas da criança: a exterioriza- 
ção em abundantes perguntas desse embaraço fundamental com esse acaso que tem relações com a causa. Não se trata nem de puro determinismo nem de pura contingência, e sim da dimensão de "uma causa cuja eficácia depende de um consentimento” (FREIRE \& LUSTOZA, 2005, p.37) que confere a possibilidade de perguntar pela intencionalidade e pela responsabilidade do sujeito.

Ademais, Piaget, ao ler no encontro com o acaso um fracasso do sujeito frente a essa dimensão, parece nos sugerir, muito sutilmente, um fracasso da criança, nessa fase, diante da modalidade do pensamento racional fundamentado ou na finalidade ou na causa eficiente. Ao observar que a criança, nesse período, diante dessa dimensão do acaso, encontra a saída, já referida antes, e não a saída do pensamento racional do adulto, argumenta que essa matriz das suas incansáveis perguntas "coloca em evidência o caráter ainda egocêntrico de seu pensamento" (PIAGET, 1964, p.30).

\section{FREUD COM LACAN SOBRE OS PORQUÊS DA CRIANÇA}

Ao ler "Os três ensaios sobre a teoria da sexualidade" (FREUD,1905/1996), podemos dizer que, a partir do enfoque psicanalítico, a atividade intelectual se estrutura a partir da atividade sexual na própria medida em que a sexualidade e a atividade investigatória se encontram articuladas na primeira infância (SANTIAGO, 2005).

Nessa direção, Freud reivindica que o primeiro surgimento da vida sexual do sujeito na infância, entre os 3 e os 5 anos de idade, apresenta como um dos resultados a atividade investigatória da criança que não é outra coisa senão sua curiosidade sexual. Abertas as portas dessa atividade, todo o campo da sexualidade desperta a curiosidade na criança. Tal atividade de pesquisas sexuais estruturada em uma série intermináveis de porquês é, de acordo com indicação de Freud, a matriz fundante de toda a atividade intelectual posterior da criança, que ocorre na entrada dela no período de latência: período entre o quinto ano de vida e a puberdade.

Não é por acaso que a leitura e a escrita são adquiridas justamente nesse período inicial do referido período de latência. Assim, a partir de indicação de Freud, a curiosidade sexual precisa ser refreada, inibida, para que a criança possa canalizar seus interesses para outras coisas e aceder ao desenvolvimento cognitivo. Ao ler Freud, podemos concluir que tal freio nessa intensa curiosidade sexual, nesses porquês incansáveis da criança, é colocado pela topada desse sujeito com o estrutural impossível de saber, introduzido pela dimensão do enigma no percurso dessas investigações infantis.

Mas Freud fala dos porquês somente no âmbito da curiosidade sexual, e isso deve ser levado em consideração se queremos estabelecer uma interlocução entre 
a teoria piagetiana do egocentrismo infantil e o que a psicanálise de Freud com Lacan teria a dizer sobre isso, dado que os porquês na fase egocêntrica de que nos fala Piaget se dão no âmbito geral.

No entanto, encontramos uma saída para esse impasse - diga-se de passagem uma saída que legitima a nossa interlocução - , na abordagem de Lacan a esses porquês, na própria medida em que Lacan (1964a/1988) também toma os porquês infantis no âmbito geral.

Assim, se Freud fala da curiosidade, restringindo-a à dimensão da curiosidade sexual, com Lacan (idem), no seu seminário Os quatro conceitos fundamentais da psicanálise, podemos dizer que os porquês intermináveis da criança implicam uma curiosidade que toca no incompreensível, portanto, na inconsistência do saber no Outro, que o sexo e a morte (mas não somente esses temas), por excelência, testemunham. A partir da perspectiva psicanalítica de Freud com Lacan, é a pergunta pelo enigma do desejo do Outro introduzido pelo encontro sempre traumático com o ponto de falta no seu saber que se deve ler na curiosidade sexual irrefreada na criança, da qual nos fala Freud. Dessa forma, de acordo com uma leitura psicanalítica, o sujeito infantil, diante do impossível de saber que toca no incompreensível, portanto, na castração do real, não prossegue nos seus porquês intermináveis, e seus esforços desembocam em certo recuo diante de suas investigações, que nessa época são, sobretudo sexuais. Certo recuo necessário para a canalização dos seus interesses para outras coisas e para seu acesso ao desenvolvimento cognitivo.

Esse impossível de saber que diz do ponto de falta no saber do Outro introduz a inconsistência do Outro: o Outro não sabe tudo. Essa inconsistência é introduzida pela sustentação do enigma, pela sustentação da pergunta ao invés do fornecimento de respostas aos porquês da criança. Tal abordagem, cuja matriz é freudiana, que introduz a dimensão fundamental da inconsistência do saber no Outro, no acesso às aprendizagens, nos sugere a necessidade de precisão sobre o estatuto do saber no Outro, já que, por outro lado, é notório e amplamente aceito que a transferência, ou seja, a suposição de saber no Outro é condição para que ocorra a aprendizagem.

Lacan (1972-3/1996), de um lado, institui o Outro como lugar de suposição de saber e, de outro, aponta para o ponto de falta no saber do Outro, ponto que toca no impossível do real, que, ao ser sustentado em ato, funda possibilidades, inclusive a possibilidade de aprender, que é o que nos interessa nessa discussão. Daí então é possível pensar que o Outro é estruturalmente o lugar da suposição de saber, cujo paradigma é a suposição de saber em Sócrates por Alcibíades no Banquete, de Platão (PLATÃO, s.d./1995). Mas esse saber é não todo, portanto, esse Outro do saber é castrado. Ele não sabe tudo. A castração do Outro relaciona-se a um ponto opaco no seu saber. 
Esse ponto de falta no saber do Outro introduz o encontro sempre traumático do sujeito com o enigma do desejo do Outro que introduz a operação de separação, uma das operações de constituição do sujeito no campo do Outro (LACAN, 1964a/1988, 1964b/1998), cuja abordagem ultrapassa o limite do presente artigo. Essa falta encontrada no Outro surge nas lacunas, nos buracos do discurso do Outro, nos pontos em que algo resiste ao efeito de cola. "O que ele deseja quando me diz isso?" (LACAN, 1964a/1988). Desejo do Outro que está para além ou para aquém no que esse Outro diz, do que ele intima, do que ele faz surgir como sentido.

"Nesse intervalo cortando os significantes, que faz parte da estrutura mesma do
significante, está a morada do que, em outros registros de meu desenvolvimento,
chamei de metonímia. É de lá que se inclina, é lá que desliza, é lá que foge como
o furão, o que chamamos desejo. O desejo do Outro é apreendido pelo sujeito na-
quilo que não cola, nas faltas do discurso do Outro, e todos os porquês da criança
testemunham menos de uma avidez da razão das coisas do que constituem uma
colocação em prova do adulto, um por que será que você me diz isso? Sempre re-suscitado
de seu fundo, que é o enigma do desejo do adulto." (LACAN, 1964a/1988, p.203)

Nesse ponto, cabe dizer que, de acordo com Correa \& Pinheiro (2010, 2013), a questão não consiste em não fornecer de modo nenhum à criança as explicações que suas investigações e sua curiosidade irrefreada requerem. O problema é que o embaraço do educador desemboca com frequência em posições que obstruem a invenção de um saber faltante a partir do referido radical nãosabido. Tais posições vão de um extremo a outro, ou negando completamente qualquer explicação à criança, tratando, por exemplo, o assunto sexual como um tabu, deixando-a no completo vazio, ou lhe dando explicações excessivas, permanecendo a criança sabendo demais, sem a possibilidade de sustentação de um ponto de falta nesse saber, fundamental para causar o seu "seguir adiante" — coisa que no nível cognitivo se manifesta pelo ato de aprender. Nessa posição educativa idealizante, de querer explicar tudo, não é considerado que, mesmo querendo, esse "tudo" é estruturalmente impossível: nenhuma explicação será esclarecedora o suficiente. Mas, ainda assim, o "saber demais” introduz consequências que podem ser paralisantes.

Embora acreditemos que já esteja rascunhado, é importante dizer de modo explícito, nesse ponto, que o saber do qual fala Lacan é um saber inconsciente cuja possibilidade de invenção se dá a partir do já referido encontro sempre traumático do sujeito com o enigma do desejo do Outro, "Ele me diz isso, mas o que é que ele quer?" (LACAN, 1964a/1988, p.203), introduzindo a já referida operação de separação (LACAN, 1964a/1988, 1964b/1998). Somente a partir desse encontro 
faltoso com a castração do Outro (LACAN, 1972-3/1996), que introduz o seu desejo enigmático, é que se funda em ato a possibilidade de o sujeito infantil inventar um saber faltante a partir de pedaços de real (VIDAL, 1999). A partir daí, há uma possibilidade de apaziguamento do excesso de embaraço do sujeito infantil com o enigma do desejo do Outro, muito frequentemente encontrado nos quadros de dificuldade de aprendizagem.

A despeito da diferença existente entre saber e conhecimento, para o que nos interessa aqui, importa apontar, conforme indicação de Corrêa (2011), que não há possibilidade para a criança "sair do excesso de embaraço com o material que lhe é demandado aprender no nível do conhecimento se há excesso de embaraço com o ponto de falta no saber do Outro que diz da verdade do seu desejo: que o Outro, educador, não sabe tudo” (p.800).

Além disso, conforme apontado, Freud (1905/1996) indicou a relevância da estrutural inibição sexual para a criança aceder à aprendizagem. Se dissemos que a aludida estrutural inibição sexual abordada em termos de um freio sobre a irrefreada curiosidade sexual da criança pode ser interpretada como o mencionado encontro sempre traumático da criança com o ponto de falta no saber do Outro, ele termina por deixar rascunhada a possibilidade de ler essa sugerida "relação entre a estrutural inibição sexual e o acesso ao desenvolvimento cognitivo como uma relação entre o aludido encontro faltoso com o saber inconsistente no Outro e o ato de aprender" (CORRÊA, 2011, p.800).

"A possibilidade da invenção de um saber faltante a partir do encontro com o ponto de falta no saber do Outro, dado que coloca em jogo o reposicionamento do sujeito diante do Ideal, que, de acordo com Lacan (...), escamoteia a aludida hiância no saber do Outro, comporta nela a subversão da relação da criança com o conhecimento e, por conseguinte, com a aprendizagem. Tal subversão confere a abertura para que a aprendizagem possa não se exaurir em modelamento que diz de uma dimensão idealizante muito frequentemente encontrada no campo educacional e para que o sujeito possa se sentir causado a colocar algo de seu naquilo que recebe do Outro." (CORRÊA, 2011, p.800-801)

Feito esse importante destaque, podemos continuar o percurso pretendido dizendo que, nessa direção, a presente seção argumenta que a nuance introduzida pela análise dos porquês infantis permite dizer que embora a aprendizagem se sustente na suposição de que o Outro sabe, nos quadros de dificuldades de aprendizagem podemos verificar padecimentos nas aprendizagens introduzidos pela ausência da sustentação do enigma introduzido pelo ponto de falta do saber no Outro, cuja matriz, podemos dizer a partir desse artigo, são as investigações infantis com todos os seus porquês já assinaladas e a posição do Outro diante 
das incansáveis perguntas da criança. Podemos encontrar aqui, nesse percurso feito, a importância fundamental no tratamento de inúmeras dificuldades de aprendizagem, da sustentação desse enigma, na própria medida em que tal dimensão é fundamental para que a criança possa aceder ao saber faltante (não no sentido de recuperação e sim do saber em uma dimensão radical de hiância) e, por conseguinte, possa aceder à aprendizagem.

\section{ALGUMAS CONSIDERAÇÕES SOBRE OS PORQUÊS DA CRIANÇA EM PIAGET E NA PSICANÁLISE DE FREUD COM LACAN}

Como já referido na seção anterior, Piaget lê no encontro com o acaso, presente nos incansáveis porquês da criança, uma dimensão de fracasso do sujeito frente a essa dimensão, parecendo com isso nos sugerir um fracasso da criança, nessa fase, diante da modalidade do pensamento racional fundamentado ou na finalidade ou na causa eficiente.Cumpre dizer que nesse ou trata-se, como já foi referido, de um “ou”exclusivo, ou seja: um ou outro, mas não ambos (COPI, 1978) que remonta igualmente a Aristóteles no seu tratado Da interpretação (ARISTÓTELES, s.d/2005), em que ele, nesse tipo de proposição, exclui a possibilidade de um terceiro: um e outro ao mesmo tempo. Como também já referido na seção anterior, ao observar que a criança, nesse período, diante dessa dimensão do acaso, encontra a saída já abordada, e não a saída do pensamento racional do adulto, Piaget argumenta que essa matriz das suas incansáveis perguntas “coloca em evidência o caráter ainda egocêntrico de seu pensamento” (PIAGET, 1964, p.30).

Com essa abordagem, Piaget nos sugere muito sutilmente a mesma visada de Wittgenstein (1969/2000) na filosofia da linguagem, mais especificamente, no seu livro Da certeza, em que podemos encontrar, ainda que mínima, uma discussão dos porquês infantis, dentro de uma abordagem da certeza e da dúvida, na qual a legitimidade desses dois estados de espírito estaria ancorada na dimensão da racionalidade. Importa-nos aqui essa referência, porque nos ajuda no avanço da questão.

Wittgenstein (1969/2000), ao argumentar que a certeza precede as razões dadas por alguém para justificar suas reivindicações, assevera que a certeza pode ser reivindicada por alguém sem ele necessariamente possuir razões para isso. Ele não precisa ter fundamentos para sua certeza (CORRÊA, 2008). A criança aprende, acreditando no adulto. A dúvida vem depois da crença (WITTGENSTEIN, 1969/2000, p.57, \&160). “Uma criança aprende que há informadores fidedignos e não fidedignos muito mais tarde do que aprende fatos que lhe são contados" (idem, p.53 e 143). Ou seja, a dimensão da mentira, do engano e com isso a da dúvida é introduzida na criança somente depois da sua convicção no consistente sistema que se constitui para ele por meio do que o adulto conta 
e ensina - substrato de todas as suas perguntas e afirmações. Esse consistente sistema, por mais que inclua em sua estrutura algumas coisas mais ou menos suscetíveis de alteração, encerra algumas outras coisas que permanecem inabalavelmente firmes, que são as proposições, que são ponto assente ${ }^{1}$ para nós. A criança não aprende explicitamente as proposições que são ponto assente para ela, e sim descobre-as "subsequentemente como o eixo em torno do qual roda um corpo. Este eixo não está fixo no sentido de haver alguma coisa a segurá-lo, mas o movimento em torno dele determina sua imobilidade" (WITTGENSTEIN, 1969/2000, p.55 e 152).

O ponto assente e com ele a certeza são dados de saída. A consideração de pontos assentes faz parte do nosso método de dúvida e investigação. Se uma criança puder duvidar imediatamente daquilo que lhe ensinam, isso só pode significar que ela era incapaz de aprender certos tipos de jogos de linguagem (idem, p.85 e 283). Nessa perspectiva, a falência dos pontos assentes faria, por exemplo, a aprendizagem da criança não avançar, na própria medida em que na ausência da operacionalidade deles, o aluno não deixa que o professor lhe explique nada, ao interrompê-lo continuamente com dúvidas acerca da existência das coisas, significado das palavras etc. Dúvida vazia de sentido que não conota sua pergunta como legítima, pois as perguntas legítimas que formulamos e as nossas dúvidas que conotam tal legitimidade dependem de proposições que, por estarem isentas de dúvidas, serem "como que dobradiças em volta das quais as dúvidas giram” (WITTGENSTEIN, 1969/2000, p.99 e 341).

Nesse tipo de situação, o aluno demonstra que "não aprendeu a procurar coisas. E, do mesmo modo, o aluno não aprendeu como fazer perguntas. Não aprendeu o jogo que queremos lhe ensinar" (idem, p.91 e 315). Mesmo usando por vezes o termo 'crença', o sentido conotado concerne aos pontos assentes, portanto, à convicção. Tanto que Wittgenstein diz: “o fato de que há coisas que são pontos assentes para mim não se radica na minha estupidez ou credulidade” (WITTGENSTEIN, 1969/2000, p.73 e 235). Portanto, a criança aprende

\footnotetext{
${ }^{1}$ Para Wittgenstein, "pontos assentes" (expressão extraída da tradução portuguesa da obra em discussão Da certeza), são pontos legitimados pela racionalidade que não admitem dúvidas. Tais pontos assentes consistem "de coisas que ouvimos e lemos por toda a nossa existência; consistem de coisas que herdamos e aprendemos de quem ocupou o lugar de autoridade em nossas vidas; coisas das quais não temos, em geral, nenhuma razão para duvidar. Mas, em Da certeza, o filósofo também argumenta que é impossível refutar o ceticismo apontando proposições que são absolutamente certas, como (...) fez Descartes, quando declarou: “Penso, portanto, não tenho dúvida alguma de que existo", porque é possível duvidar de qualquer certeza individual em tais e tais circunstâncias, a partir de razões fundamentadas em experiência prévia. Argumenta que o fato de tais proposições serem consideradas certas indica apenas que elas desempenham papel indispensável, normativo, em nossos jogos de linguagem e que, portanto, não podem ser tomadas para expressar verdades metafísicas (AUDI, 1995)" (CORRÊA, 2010, p.237-238).
} 
uma enorme quantidade de coisas e aceita-as na base de autoridade de homens. Apenas subsequentemente, por meio da racionalidade, considera que algumas dessas coisas se confirmam e outras não, de acordo com sua própria experiência.

Seguramente, se Piaget fala de "monólogos", seja nas conversações travadas entre crianças, seja quando ela está falando sozinha, Piaget não faz a mesma leitura que Lacan, na própria medida em que para Piaget os referidos “monólogos" têm como matriz o egocentrismo infantil entre 2 a 7 anos de idade. Lacan chama esse reivindicado "discurso egocêntrico" de erro, pois para ele essa noção é um contrassenso, na própria medida em que "a criança, nesse famoso discurso que podemos registrar num gravador, não fala para si, como dizem” (LACAN, 1964a/1988, p.197).

Com isso, Lacan não coloca em dúvida de modo nenhum que de fato, como Piaget argumenta, a criança nesse chamado “discurso egocêntrico” não se dirige a outro, em termo de "uma repartição teórica que se nos deduz da função do eu e do tu" (LACAN, 1964a/1988, p.197). Mas, para Lacan, o fato de a criança nesse referido discurso não estar na dimensão do diálogo não exclui outra relação dela com o Outro simbólico da linguagem que está para além de toda e qualquer relação dual. Não exclui a relação dela com o Outro como um lugar simbólico para onde ela se dirige para escolher os significantes que lá estão. E por isso mesmo o seu discurso não é "egocêntrico", e sim a partir do Outro e também endereçado ao Outro na própria medida em que, por exemplo, todos os seus porquês visam à colocação em prova desse Outro como suposto lugar do saber. “É preciso que haja outros lá — é quando estão todos lá, os pequenos, todos juntos a se livrarem, por exemplo, de joguinhos de operações como lhes dão em certos métodos ditos de educação ativa, é aí que eles falam - eles não se dirigem a tal ou tal pessoa, eles falam, se vocês me permitem o termo, para lá, canto da coxia” (LACAN, 1964a/1988, p.197).

Importa muito dizer que na dimensão dos porquês infantis, nosso percurso indicou que tanto Piaget quanto Lacan se depararam com a dimensão do acaso a partir da Física aristotélica. Como já foi dito, isso não é qualquer coisa, ainda que o que os dois vão fazer a partir desse encontro são duas coisas distintas, na própria medida em que Piaget não toma sob consideração a tiquê, uma das causas acidentais descrita por Aristóteles, que se refere ao acaso com certa dose de deliberação.

Como já dissemos - mas importa muito dizer de novo, mesmo que incorrendo na repetição - , pensamos que ainda que as perguntas infantis dentro dessa matriz dos porquês intermináveis ocorram em relação a coisas que não comportam certa dose de deliberação, a tomada sob consideração da tiquê introduz nova nuance, a saber, a nuance que diz do embaraço infantil com esse acaso que não abole as suas relações com a causalidade. 
Vimos na seção anterior que é justamente esse embaraço que Lacan (1964a/1988) privilegia na sua análise dos porquês infantis, na própria medida em que a pergunta pelo desejo do Outro que é o que ele diz estar em jogo nessas incansáveis perguntas é introduzida justamente pela topada do sujeito com o ponto de falta no saber do Outro, ou seja, sua castração. Pois, se nesse mesmo seminário, Lacan esclarece que essa topada com o real refere-se à incidência da tiquê, na própria medida em que nesse encontro faltoso que diz respeito à dimensão do que se repete como falta, para além dos signos e do seu retorno, o que está em jogo é o acaso com certa dose de deliberação, então a pergunta pelo desejo do Outro introduzida pelo encontro tíquico (tiquê), presente nos porquês infantis, trata de uma pergunta pelo acaso, que não abole as suas relações com a causalidade, a saber, a causa do desejo do Outro.

Com Lacan, estamos autorizados a dizer que é isso que podemos ler nas incansáveis perguntas da criança: a exteriorização em abundantes perguntas desse embaraço fundamental com esse acaso que tem relações com a causa. Não se trata nem de puro determinismo nem de pura contingência, mas sim de um impossível de saber que toca no incompreensível, o impossível do real, fonte de embaraço. Como já assinalado e discutido, esse impossível de saber quando escamoteado pela dimensão idealizante (LACAN, 1962-3/2005) coloca muitas vezes em jogo padecimentos nas aprendizagens devido à ausência da sustentação do enigma que introduz o saber inconsistente do Outro, cuja matriz são as investigações infantis com todos os seus porquês e a posição do Outro diante dessas incansáveis perguntas.

Recebido em 26/4/2012. Aprovado em 30/10/2012.

\section{REFERÊNCIAS}

ALBERTI, S. (1995) Esse sujeito adolescente. Rio de Janeiro: RelumeDumará. ARISTÓTELES. (s.d./1999) Física (Livros I e II). São Paulo: IFCH/Unicamp. (s.d./2005). "Da Interpretação", in Órganon, São Paulo: Edipro, p.81-110.

COPI, I. M. (1978) Introdução à lógica. São Paulo: Mestre Jou.

CORREA, C.R.G.L. (2008) Certeza e crenças delirantes. Mental Revista de Saúde Mental e Subjetividade, 6(10). Barbacena: Unipac, p.41-67.

(2010) A temporalidade entre a certeza e a dúvida na filosofia e na psicanálise. Revista Cadernos de Psicanálise (SPCRJ),26(29). Rio de Janeiro: SPCRJ, p.233-261.

(2011) A inauguração da interlocução entre a educação e a psicanálise no Brasil: Arthur Ramos, transferência, Ideal e Autoridade. Revista Psicologia USP, 22(4). São Paulo: USP, p.789-811. 
\&PINHEIRO, G. S. (2010) Período de latência e tempo para compreender nas aprendizagens. VIII Colóquio Internacional do Lepsi e II Congresso da Ruepsy "O declínio dos saberes e o mercado do gozo: a psicanálise na educação”, 2010, São Paulo. Anais... São Paulo: Faculdade de Educação/Instituto de Psicologia USP. . \& . Período de latência e tempo para compreender nas aprendizagens. Revista Psicologia em Estudo, 18(1), p.61-69.

FREIRE, A. B. \&LUSTOZA, A. Z. (2005) A psicanálise entre a razão e a causa. Pulsional Revista de Psicanálise, ano XVIII, n.184. São Paulo: Editora Escuta, p.28-39.

FREUD, S.(1905/1996). “Três ensaios sobre a teoria da sexualidade”, in Edição standard brasileira das obras psicológicas completas, v.VII, Rio Janeiro: Imago, p.118-229.

LACAN, J. (1962-3/2005) O Seminário, livro 10, A angústia. Rio de Janeiro: Jorge Zahar.

. (1964a/1988) O Seminário, livro11, Os quatro conceitos fundamentais da psicanálise. Rio de Janeiro: Jorge Zahar. (1964b/1998) "Posição do inconsciente", in Escritos. Rio de Janeiro: Jorge Zahar.

(1972-3/1996) O Seminário, livro 20, Mais, ainda. Rio de Janeiro: Jorge Zahar.

LA TAILLE, Y. de. (1992). “Desenvolvimento do juízo moral e afetividade na teoria de Jean Piaget", in et al. Piaget, Vygotsky e Wallon: Teorias psicogenéticas em discussão. São Paulo: Summus, p.47-73.

LOPES, A. G. L. \& VINHEIRO, V. (1999) Repetição e a clínica. Revista Escola Letra Freudiana, ano XI, n.10/11/12. Rio de Janeiro: Escola Letra Freudiana, p.78-83.

PIAGET, J. (1964) Seis estudos de psicologia. Rio de Janeiro: Forense Universitária.

PLATÃO. (s.d./1995) O banquete. Rio de Janeiro: Bertrand Brasil.

SANTIAGO, A. L. B. (2005) A inibição intelectual na psicanálise. Rio de Janeiro: Jorge Zahar.

VIDAL, E. A. (1999) Um outro saber. Revista Escola Letra Freudiana, ano 17, n.23. Rio de Janeiro: Escola Letra Freudiana, p.21-27.

WITTGENSTEIN, L. (1969/2000) Da certeza. Lisboa: 70.

Cristia Rosineiri Gonçalves Lopes Correa

crlopes2001@yahoo.com.br 
